\title{
START HERE> An Interdisciplinary Introduction to Electronic Literature
}

\author{
Michelle Citron, Kurt Heintz, Niki Nolin, Scott Rettberg, Andrew Stern, \\ Joseph Tabbi, and Rob Wittig
}

The hypertext solution ... retains and puts back together the great traditions of literature and scholarship, traditions based on the fact that dividing things up arbitrarily just generally doesn't work.

-Ted Nelson, Computer Lib/Dream Machines (1974)

Before reading what follows, I suggest that you turn on your networked computer and prepare to visit some territories that have not yet been clearly demarcated. START HERE $>$ is more cultural snapshot than cultural study, more a map of places to explore than an explanation of what you'll find there. This is an article intended

Michelle Citron is a Professor in the Department of Radio/Television/Film at Northwestern University, Associate Dean of The Graduate School, and Director of the Center for Interdisciplinary Research in the Arts. Kurt Heintz is a writer, performer, and new media artist, who founded the e-poets network and whose work has appeared in the anthology Rude Trip: The HamburgChicago Literary Expedition (Edition 406, 2001). Niki Nolin works and teaches in the Academic Computing Department of Columbia College, Chicago. Scott Rettberg is Assistant Professor of New Media Studies in the Literature program at Richard Stockton College, as well as cofounder of the Electronic Literature Organization and co-author of The Unknown: A Hypertext Novel (1998-2001) and The Unknown: An Anthology (The Unknown Press, 2002). Andrew Stern is a designer and programmer for PF.Magic in San Francisco. Joseph Tabbi is the author of Cognitive Fictions (Minnesota, 2002) and co-editor of Reading Matters: Narrative in the New Media Ecology (Cornell, 1997), as well as co-founder of the electronic book review and Associate Professor of English at the University of Illinois, Chicago. Rob Wittig is co-founder of the literary electronic bulletin board system IN.S.OMNIA and author of Invisible Rendezvous: Connection and Collaboration in the New Landscape of Electronic Writing (Wesleyan, 1994). 
for practical use more than quiet contemplation. START HERE $>$ is a remediation of an event which itself seemed strangely out of context: a guided tour to some innovative contemporary experimental literature for the computer presented in the context of a digital culture festival, Version $>02$, held April 18-20, 2002 at the Museum of Contemporary Art, Chicago. As I review START HERE> now, seven months after its initial presentation, the project reminds me of the many discussions and debates on electronic literature and electronic textuality that a small group of writers, critics, and artists gathered for on a bimonthly basis from 1999-2002 at Moti Mahal, an Indian restaurant on Clark Street in Chicago. START HERE> presents many of the works that served as fodder for those conversations in the form of a catalog of Web sites and electronic narratives on CD-ROM. The works described here are a representative sample of the many forms of expression loosely grouped under the umbrella term "electronic literature." We present these works not as a canon, but as a set of experiments in electronic literature. START HERE $>$ is a representative sample that should generate further questions rather than clear answers.

Some of the questions that the curators of this project regularly asked each other over Sag Paneer and Lamb Vindaloo:

- What makes a given work particularly electronic?

- What makes a given work particularly literary?

- Is the Internet primarily a distribution system, or should it be understood as a materially distinctive artistic medium?

- What audience does electronic literature serve?

- How can our work reflect the ways that the network environments have changed the way that our audience reads and writes?

- How do we strike a balance between image and text; form and content; interface and narrative?

- How can writers, designers, artists, filmmakers, critics, and theorists find a common language to discuss interdisciplinary work made for electronic media? In what discipline or disciplines should that common tongue be based?

The professions of the curators range from fiction writer and non-profit executive to filmmaker and Associate Dean at Northwestern University to design consultant and electronic publisher to Artificial Intelligence programmer to editor and Associate Professor of English at the University of Illinois-Chicago to multimedia applications and fine arts teacher at Columbia College to performance poet and freelance Web designer. I asked each curator to describe one project that he or she had produced or participated in and three projects produced by others. Within each set of works, you will find a particular interest set: Michelle Citron's selections reflect an interest in cinematic interactive narratives; Kurt Heintz explores the network as a distribution system for performance poetry; Niki Nolin focuses on visual poetics; my selections illustrate different ways that writers are using the interface as metaphor; the works that Andrew Stern describes are based on Artificial Intelligence; Joseph Tabbi's selections reflect his interest in the network as a "literary re-mixing" environment; and Rob Wittig's selections reflect his interests in "network styles" and "experience design." 
Electronic literature is a truly experimental kind of literature. It's entirely likely that in a decade or two the different types of experiments described below will no longer sit so easily alongside each other but will instead each be based in one of the new disciplines that are just now beginning to take shape in universities: the new media studies programs based in literature departments, the interactive cinema programs based in film schools, the digital arts programs based in visual arts and design programs, and so forth. START HERE $>$ is a synecdoche of a larger process currently taking place at the borders of many disciplines, as we look outside our own traditions and ask others for suggestions on where we might start our process of reinvention.

-Scott Rettberg

\section{Michelle Citron}

The four pieces presented here explore the meaning of storytelling in an interactive, digital environment. Borrowing from the more linear arts of film, video, and literature, their central concern is with the intimate, the personal, and the relational.

\section{Michelle Citron, Queer Feast (1999-present)}

Work is on CD-ROM. Information is available at: <http://www.rtvf.northwestern.edu/ faculty/citron>.

Queer Feast is a five-course meal: a mosaic of contemporary lesbian life played out through its contradictions of class, race, desire, and the banalities of daily life. Each of the five pieces that will eventually make up the feast represent five evolving experiments in narrativity. Two of the courses, As American Apple Pie and Cocktails \& Appetizers, characterize how we build stories from fragments overheard. Apple Pie tells its tale through twenty-two scenes randomly accessed by the viewer/ player, from which a narrative of the characters' family life can be constructed. Apple Pie is open-ended; a different story is constructed on each viewing. Played one time, Monica and Lucille live happily ever after; another time, their relationship does not survive; and in yet another play ambiguity prevails. Cocktails \& Appetizers uses a different narrative strategy. You eavesdrop on a multitude of conversations during an art opening cocktail party. From these snippets of both relevant and inconsequential gossip, you construct, retroactively, a story of the main characters, their relationships, and their milieu. Cocktails is about falling into lust and love; Apple Pie is about what happens after the first kiss is over.

\section{Arlene Stamp, Modern Mother (1998)}

$<$ http://www.vanitygallery.com>

In Modern Mother storytelling is both the subject of the piece, as well as its form of delivery. Stamp conducted audio interviews with her mother in 1995, literally asking, "Tell me a story about your life." What her mother tells is not a story but rather a series of stories, or fragments of stories, that make up the narrative of her life. The 
tales, like all family tales, reveal emotionally charged secrets: the dream to dance on stage, the experience of molestation, an abortion gone awry. The user can only access these stories by entering into a closet, the space where secrets are hidden. And it is the user who decides how much to hear. Do you want to know more about "D is for dream," "H is for Hell," or "O is for oozing"? The choice is yours. Stamp provides a cultural context to these very personal stories by juxtaposing them against the popular music of her mother's era: pop culture representations of a romanticized life of love, intimacy, and family.

Modern Mother borrows from the long tradition of women's personal documentary, particularly those in which a woman searches to understand the life of her mother, her relationship to it, and, through that process, her own life. By using an interactive form, Stamp drives home the idea that we can only understand someone else's life story through fragments and that what we hear is, in part, determined by us. The stories are told to Stamp (the daughter) and we (the viewers) in bits and pieces. The narrative revealed is created in the space between storyteller and story listener.

Marsha Kinder and The Labyrinth Project, Mysteries and Desire: Searching the Worlds of John Rechy (2000)

Work is on CD-ROM. Information is available at: <http://www.annenberg.edu/ labyrinth/electronic.html $>$ and $<$ http://johnrechy.com $>$.

Marsha Kinder's Mysteries and Desire: Searching the Worlds of John Rechy explores the life, work, and milieu of the writer John Rechy. This is a world where the sexual folds back onto the spiritual, the psychological, political, and cultural dance around each other, and the border between fiction and memoir all but disappears. Drawing on film's lush aesthetic of deep focus, close-up, moving shots, and realist images, the work is at once a memoir, an oral history, a work of fiction, a visual collage of two cultures (Chicano and gay), and a representation of the inner life of a writer.

Mysteries and Desire presents fragments of literature, historical film, family photographs, memories, gay iconography, and religious imagery to create a new, more fluid form of storytelling. The piece is divided into three spaces: memories, bodies, and cruising. By entering into these spaces, level after level of imagery, words, and meaning are revealed. The user moves through VR environments: a collage of family and historical photographs, a town square. Click on a link and you jump deeper into the space: the inside of a church, down a dark alley. You never know if the click of the mouse will jump into a new world, animate a character, or bring forth a memory.

Annette Barbier and Drew Browning, Home (2001-present)

Work is on CD-ROM (recommended) and also available for high-bandwith access on-line at: <http://www.unreal-estates.com>.

Home explores the meaning of home, the secrets revealed there, and our emotional 
relationship to both the place and the intimacies contained therein. A house is for sale; it has been abandoned. Yet it reverberates with the memories of those who lived there and whose most private moments still inhabit the half empty spaces. The user overhears snippets of emotionally charged family conversations, moves down dark corridors and enters into surprising rooms. You eavesdrop, learn secrets, watch. From these fragments the story of this specific home is pieced together, as well as the meaning of home itself.

Using VRML, Home invites you to move through the pretty, flat suburb and into the 3-D world inside the house. This home, like all homes, is constructed from rooms and objects: a coffee cup, a telephone, a moth, a postcard, a slice of pie, a family photo, a bottle of alcohol, a nightlight, a bedside stand, children's toys, a bathroom mirror, a bathtub, and even a window to the outside. These objects are links to the work of fourteen different artists who were invited by Barbier and Browning to create a piece on the meaning of home. Many of these works are fragments from longer films and videos. Collectively they present different points of view on the psychological, social, and cultural dimensions of home. From this mosaic, a complex narrative of home and its meaning is created.

\section{Kurt Heintz}

In the 1980 s, I was caught up in the movement that has since evolved into contemporary slam poetry. At that time, we Chicago poets were working for the recovery of spoken word. Parties to the slam revolution felt that words in print and people of letters had put poetry to sleep. Poetry wasn't animated or, for that matter, engaging any more, or at least that was the polemic that got us out to write and perform all over town in those years. Today, the slam poetry revolution has since orbited the planet in several directions at once. Poets today are prattling, and poetry is, ostensibly, awake.

Today, performance poetry can be studied in on-line workshops, reviewed in schools, cited as whole sound samples in dissertations, and (yes) even reliably quoted on listservs, because we can now distribute the same performance consistently to many people at many different times. Poetry will become much more aural as artists and audiences respond to phenomena that text alone cannot readily describe. Where audio technology is already a given feature of daily life, such as in hip-hop culture, the poetry is already less narrative (like paper-based text) and more sonic (a signature of new media).

Further, the evolving critique is becoming as placeless as the Web itself. For example, a website dedicated to Chicago poetry can, presumably, broadcast our city's image back to itself. But in my experience, opening the dialogue to broader consideration truly expands the audience and artistry. Publish two poets side-byside from different cities or, better still, put them in the same reading through a videoconference, and deeper dialogues naturally emerge. I've even seen this happen with kids, when high school students have read for each other on-line, and discussions about rape, security in the schools, and street gangs erupt quite spontaneously. Suddenly, it's not just about the poetry (or the poet) but the contrasts 
between societies. People come in for the poetry but go home with a culture.

Below are three current sites that illustrate one evolution of audiopoetry on the Web. Taking a self-promotional nod from Beau Sia, I've spiked this short list with one of my own links. I do so with the interest of cultivating an active and critical discussion of spoken word. Please surf and enjoy but, whatever you do, share your ideas-out loud.

Loss Pequeo Glazier (editor), Electronic Poetry Center (1995-present) $<\mathrm{http}$ ///wings.buffalo.edu/epc/> and <http://epc.buffalo.edu/sound/>

$E P C$ is one of the Web's true genesis points for on-line poetry. $E P C$ has been collecting and organizing poetry on-line since the mid-1990s. EPC organizes as much as it can into links, and in some ways resembles a huge "link farm" of poetry. Many EPC links feature audio. The design and organization of the site is strictly functional. In this sense, $E P C$ follows the Internet portal model for a website.

$E P C$ just about had the corner on on-line audiopoetry in the early days. $E P C$ continues as an authoritative resource on many poets of historical significance in the English language. Today, $E P C$ is liaising with partner websites, such as $U B U W E B$ $<$ http://www.ubuweb.com>, to deliver hundreds of audiopoems in a variety of formats, including .AU and MP3. However, in taking on so many external links, the core website requires much care to avoid "link rot."

Kurt Heintz (editor), Book of Voices (1999-present)

$<$ http://voices.epoets.net>

The $B o V$ began its life as a documentation site for videoconferenced poetry readings in the e-poets network. Poems were excerpted from documentation videos (either in video or audio form) and encoded for streaming. However, as it became clear that the Web could handle more than mere documentation, artists' entries became more involved and entertaining, evolving into full chapters that profiled artists in depth. With the "book" as an open metaphor, the BoV website follows a library model. A recent site overhaul encouraged deep linking and bookmarking.

Chapter one of the BoV launched in August 1999, just in time for the National Poetry Slams in Chicago, with a feature on Patricia Smith. Today, the BoV carries audio from about fifty local and foreign poets, most with multiple recordings, and offers links to video in its sister website, the e-poets Videotheque. BoV's approach to content is the opposite of EPC's, as $B o V$ is fairly self-contained. That exacts a different cost, however, in maintaining $\mathrm{A} / \mathrm{V}$ resources.

Jayne Fenton Keane, Slamming the Sonnet (2001-present)

$<$ http://www.poetinresidence.com/slamming >

Taking the visual and aural potentials even further, Australian Jayne Fenton Keane officially launched Slamming the Sonnet early in 2002. Keane traveled extensively in the last three years and recorded the voices of writers she encountered. She also 
embarked on an ambitious correspondence with writers abroad, soliciting audio samples from selected performance poets. The result is a collection of much contemporary spoken word, bound together by a lively, Flash-driven graphical environment. The site has earned Keane much praise in Australia, and was featured in ELO's recent State of the Arts Symposium Gallery. With its extensive animations and sound elements, $S t S$ occupies a spot somewhere between a book and a video game. Interactive features encourage viewers to play with verbal sounds as if the interface were a "busy box." It's all about literacy and inquiry as entertainment. StS follows an interactive TV model. The site's elaborate design and custom Flash animations come only with much labor. Though it's uncertain that $S t S$ will grow very much in the years ahead, we can at least enjoy it as a current benchmark for performance poetry on the Web.

\section{Niki Nolin}

When Scott Rettberg asked me to participate both as a contributor and as a curator in the electronic literature portion of the MCA Version>02 Digital Commons exhibition, I was thrilled to have an opportunity to present work with a varied group of practitioners of the electronic literature oeuvre and to present my personal sources of inspiration: interactive or non-linear poetry sites. Turning to my bookmarks, I quickly pecked through the favorites only to find most of them gone: disappeared into the digital graveyard or published and no longer free. And while sites like Poems that Go <http://www.poemsthatgo.com>, edited by Ingrid Ankerson and Megan Sapnar, house, support, and nurture the poetic contributors of electronic literature and the ELO supports artists/practitioners by providing links to sites, the sad truth is that this medium is not free and many sites are lost to unpaid domain names and hosting costs. I like to think that the artists' sites I had bookmarked, to find and hold forever, had succumbed to the speed and rate of change inherent in the medium and had just moved on. A romantic notion, but so is freedom of information. Access to the sites was paramount and necessary to my selection process.

While many beautiful sites exist that visually interpret established and historical poets, the second criteria for selection was original content. Each selection speaks with an original voice. Each voice demonstrates an honest humor. A sense of playfulness defined by the text, images, technology, and/or the interaction and navigation of the viewer. All three contain a suggestion of the erotic, the sensual juxtaposed by the medial conveyance of the work, a sense of innocence evidenced in the use of the technology, simplicity, and a convergence of reading, viewing, and interaction.

Niki Nolin and Maureen Seaton, Literal Drift (2002)

<http://206.69.161.29/literaldrift/introall.swf>

Spoken word poetry collaboratively created by Niki Nolin and Maureen Seaton, Literal Drift addresses the accumulation of sediment, the ebb and flow of life in time. Intimate whispers, mouse-overs attached to text and objects, offer viewers 
substitution and combinations as the sound randomly links and unlinks to the text.

Vicky Wong, Fearless Little Love Poems (2000)

$<$ http://www.beetleblue.com/fear.html>

Vicki Wong's playful, erotic characters give voice to questions left unasked and (sometimes) unanswered. Straightforward navigation leads to intuitive vignettes, observations on the nature of relationships, strung like tiny pearls of wisdom, curiously penetrating. Black and white questions and answers meet graphic images and ideas.

Louise McKissick, iloveyou 2000 (2000)

$<$ http://flow-digital.com/iloveyou.shtml>

3000 ladybugs in a teacup listen to whispered sweet nothings in Louise McKissick's Quicktime poem, iloveyou. The intimate, playful, and erotic visual puns of iloveyou personalize the viewing experience in this meditation on computer viruses. Feel your mouth at the cup. The bugs crawling. Strain to understand the text. See the mouth move and hear her whisper. Enmeshed in a moment, one brief moment to play again and again.

Kim Collmer, $H u b(2001)$

$<$ http://www.artic.edu/ kcollm/hub_proj/>

Kim Collmer is a sculptor living in Chicago and $\mathrm{Hub}$ was created from documentation of a physical site. Material to immaterial, objects to images. $H u b$ is an alternative journey, an exploration of fantasy. The color blue has been integral to Kim's work, in fact hard to leave behind. To me it emits clarity of vision, optimism for the journey yet to come.

\section{Scott Rettberg}

William Gillespie, Frank Marquardt, Scott Rettberg, and Dirk Stratton (including substantial contributions from Kathryn Gilligan and Paul Kotheimer), The Unknown (1998-2001)

$<$ http://www.unknownhypertext.com>

The Unknown is a collaborative hypertext novel, a writing game that developed in a mammoth parody of millennial culture. It began as a joke in the form of a game. Three friends, William Gillespie, Scott Rettberg, and Dirk Stratton, gather for a weekend in Cincinnati. Fiction writers Rettberg and Gillespie and poet Stratton discuss the sorry state of American letters, in particular the fact that their own work, the stories and poems they have spent years of their lives crafting, reaches an extremely limited readership. Drunk on bourbon and hubris, the three hatch a plan to overthrow the American publishing industry - a wretched landscape populated 
with novels about lawyers and Newt Gingrich autobiographies-with an entirely new publishing system of their own devising. They decide to publish The Unknown: An Anthology, a collection of their own best writing. Decision made, but not finding all of their best work immediately available to them, the three writers decide instead to begin writing a hypertext novel describing their own ridiculously successful, hedonistic, and dangerous book tour.

The story expands to become both the story itself and also the story of its making. The story starts to become the story not only of a book tour, but also of the way that identities are formed, take shape, and are distorted in American media culture at the turn of the Millennium. Unselfconsciously experimental and playful, the writers try their hands at writing in the styles of other writers, ripping off forms of discourse ranging from the cinematic to the epistolary. The Unknown became a thing unto itself that both none and all of its contributors created.

Alan Sondheim, assorted works in e-mail, MOO, .jpg, programs, audio, and video (early 1990s-present)

$<$ http://www.google.com/search?q=Alan+Sondheim>

Rather than linking to one particular work or collection of on-line texts, I chose here to provide a link to a Google query for Alan Sondheim. While Sondheim has produced many "works" and "collections," such as Philosophy and Psychology of the Internet <http://www.anu.edu.au/english/internet_txt/>, a "meditation on the philosophy, psychology, political economy, and psychoanalytics of Internet (computer) communication" that "focuses on virtual subjectivity, sexuality, community, and all aspects of computer interfacing," and the Alt-X eBook/POD title .echo $<$ http://www.altx.com/ebooks/download.cfm/echo.pdf>, what most fascinates about his work is not any single "finished" manifestation, but rather the way in which it is written and delivered to his audience. I think that his work is best experienced in fragments that are absorbed individually and that accrue over time. Insofar as I have an understanding of Sondheim's overall project (and I'm not necessarily sure that I can claim that), I prefer to experience it in these daily fragments, these aleatory chunks that are placed very definitively in time, rather than the "wholes" that these fragments eventually produce. I know that every day there will be some new Sondheim in my in-box, calmly insisting that I pay attention to it, if only in some subconscious corner of my brain.

While it has become fashionable among writers, designers, programmers, and others to describe oneself as a "digital artist," Sondheim is one of the few artists I would describe as a true "network artist." Sondheim is performing the network every day, on e-mail lists, in MOOs, and in chat rooms. Although Sondheim was creating writing for the computer well before the World Wide Web became ubiquitous, my feeling is that he found his home in this decentered global network. In a strange and wonderful way, Sondheim's mind has been distributed across the network. One could call his work "Portrait of the Artist as Ten Thousand Posts."

See selected Sondheim posts at: <http://www.eliterature.org/interactions/ starthere/work-alansondheim.shtml>. 
Paul Chan, Alternumerics (2000-2002)

$<$ http://www.nationalphilistine.com>

While much of the critical attention paid to electronic literature tends to focus on either hypertext or on the application of multimedia techniques to traditional forms of fiction or poetry, I'm very interested in works that use the computer in some smaller, focused way to accomplish a kind of writing that simply would not be possible without it. While I could name dozens of other works that are more fully realized as narratives or poems, or that utilize multimedia to more stunning visual, auditory, or cinematic effect, Paul Chan's font work, Alternumerics, is probably the most elegant idea for an electronic literature interface that I've run across.

The core idea of the Alternumerics project is simple: it is possible to create fonts in which each keystroke produces a sentence, a phrase, a drawing, or a different length of white space rather than representing a single character. Alternumerics, and the recent "Selfportrait of the Artist as a Font," are composed of fonts based on ideas. Using Flash, Chan includes examples of the ways in which the fonts can be used, but the true moment of interactivity with the work is when, after installing these fonts on her system, the reader begins to type, each keystroke manifesting itself on their screen as an idea fragment, a doodle, a granule of story.

Alternumerics was short-listed for the 2001 Electronic Literature Award for fiction. Although the winner, These Waves of Girls <http://www.yorku.ca/caitlin/ waves $>$ by Caitlin Fisher, is certainly more accomplished as a story in the terms we typically understand stories, Chan's work was one of several that actually challenged our judges to entirely rethink what constitutes "fiction" in an electronic literature context. I don't think that Chan would describe his own work as literature, but his oeuvre is one of a growing body of work that might be described as "designwriting," works that borrow from storytelling and/or poetry while their primary focus is on elements of design. The boundaries are blurring between the "writer," the "typographer," the "designer," and the "artist," and Chan is one of a group of strange and delightful personalities whose work encourages us to rethink those traditional categorizations.

Orit Kruglanski and Raquel Paricio, Exhale (2001)

Application for Macintosh available at: <http://www.soymenos.com/respira/exhale/> or <http://www.iua.upf.es/ okruglan/>.

Exhale, by Spain's Orit Kruglanski and Raquel Paricio, was not shortlisted for the 2001 Electronic Awards, but I would like to make note of it in this forum because, like Chan, Kruglanski and Paricio have rethought one particular element of interface to great artistic effect. Kruglanski writes interactive poems using Shockwave and also works that are developed specifically as applications for the Palm Pilot. The project was created based on Kruglanski's past work in interactive poetry and on Paricio's interest in the relation between perception and interaction. Exhale was designed specifically for the Macintosh and makes use of a noise-canceling microphone. To read the poem in its entirety, the reader must "Breathe life into it"; as the reader 
blows gently into the microphone, the words float around and assemble with the flow of the reader's breath. It's an ingenious idea for an interface, and the content of the poem relates thematically to the process of interacting with the poem.

I think that Kruglanski above nails down something that should be at the forefront of any author's thinking in creating electronic literature: that the interface can and should be understood as a poetic device. I regularly encounter works that suffer either from a) a focus almost exclusively on interface, to the exclusion of the work as a whole (like a car with great bodywork but no engine) or b) a focus exclusively on the text, with the interface treated as a strapped-on afterthought. In the most successful works of e-lit, you might not even notice the interface, because the interface is so tightly interwoven into the work that it is an aspect of the poem, rather than something you need to negotiate in order to access the poem.

\section{Andrew Stern}

Michael Mateas and Andrew Stern, Façade (2002, work in progress) $<$ http://www.interactivestory.net>

Façade is an artificial intelligence-based art/research experiment in electronic narrative; a first-person, 3D animated interactive drama performed in real-time. Using your own name and gender you play the character of a longtime friend of Grace and Trip, an attractive and materially successful couple in their early thirties. During an evening get-together at their apartment that quickly turns ugly, in which you are free to gesture and type any dialog you wish, you become entangled in the highconflict dissolution of Grace and Trip's marriage. No one is safe as the accusations fly, sides are taken, and irreversible decisions are forced to be made. By the end of this intense one-act play you will have changed the course of Grace and Trip's lives, motivating you to re-play the drama to find out how your interaction could make things turn out differently the next time.

This work is unlike hypertext narrative or "interactive fiction" to date in that the computer characters actively perform the story without waiting for you to click on a link or enter a command. Interaction is seamless as you converse in natural language and move and gesture freely within the first-person 3D world of Grace and Trip's apartment. Artificial intelligence (AI) controls Grace and Trip's personality and behavior, including emotive facial expressions, spoken voice, and full-body animation. Furthermore, the AI intelligently chooses the next story "beat" based on your moment-by-moment interaction, what story beats have happened so far, and the need to satisfy an overall dramatic arc. An innovative text parser allows the system to avoid the "I don't understand" response all too common in text-adventure interactive fiction.

Kenneth Colby, PARRY (1971)

This work is no longer accessible.

PARRY, created in 1971 by Colby at the Stanford Artificial Intelligence Laboratory, 
was one of the early software programs known as chatterbots, which simulate conversations with people. It was an attempt to model human paranoid belief systems and was based on several psychological theories of paranoia. PARRY is said to have passed the "Turing test," named for the British mathematician Alan M. Turing, who in 1950 suggested that if a computer could successfully impersonate a human by carrying on a typed conversation with a person, it could be called intelligent. In a multi-stage experiment, psychologists reliably judged $P A R R Y$ 's interactive output as being paranoid and were unable to distinguish transcripts of a session with PARRY from that of a session originating from a human patient. This was a notable advance in the simulation of human behavior. PARRY, however, never achieved the level of publicity of Joseph Weizenbaum's ELIZA, which was arguably an inferior conversationalist.

PARRY is to this day one of the best examples of designing an interactive conversational character that works with, not against, the computer's limited ability to truly understand human dialog. When PARRY does not completely understand what the user is typing (which is most of the time), the system cleverly deflects or redirects the input into its own particular interpretation (e.g., the unpredictable associations that a paranoid person may make), which may not be what the user intended but allows for a believable response nonetheless. This kind of technique can allow the characters in Facade to respond believably to human dialog they don't actually understand, within the context of their particular story.

Scott Reilly, Joseph Bates, Bryan Loyall, and Peter Weyrauch, The Playground (1996)

Information is available at: <http://www-2.cs.cmu.edu/afs/cs.cmu.edu/project/oz/ web/oz.html>.

In the mid-1990s, several interactive character prototypes were created by the $\mathrm{Oz}$ Project at Carnegie Mellon University, a group of computer science researchers developing technology to allow artists to create simulated worlds that contain rich characters and that give a human interactor the feeling of being an important part of an interesting story. The Playground was an important demonstration of their ability to build interesting text-based characters that engage in reasonably complex social behaviors. These behaviors were intended to reflect the characters' personalities, emotional state, and relationships with one another. The Playground was a simulation of three kids on a playground, one controlled by the player. Although they can engage in a number of different behaviors, one of their favorites is trading baseball cards.

The Playground is an important example of applying AI techniques towards artistic, expressive ends, versus its traditional application in problem solving. From Reilly's thesis: "The goal of building believable agents is inherently an artistic one. Traditional AI goals of creating competence and building models of human cognition are only tangentially related because creating believability is not the same as creating intelligence or realism. Therefore, the tools that have been designed for those tasks are not appropriate." Reilly focused on a breadth of relatively simple 
behaviors and emotions (e.g. a playground-level simulation of distress, joy, fear, hope, satisfaction, and so on) versus deeply modeling the complex cognitive processing for only one or two behaviors (e.g. playing chess). By limiting the amount of cognitive modeling to that which is sufficient to create the artist's desired performance, The Playground achieves robust social behaviors that use surprisingly little internal representation.

Adam Frank, Rob Fulop, Ben Resner, Andrew Stern, et al., Dogz, Catz and Babyz (1995-1999)

$<$ http://www.petz.net> and <http://www.babyz.net>

Recognizing a dearth of meaningful interactive experiences with virtual characters, a group of developers at PF.Magic in San Francisco in 1995 created the world's first virtual pets, with the design goal to create a richly interactive "illusion of life" on a personal computer within the framework of a non-goal-oriented play environment. Users control a hand-shaped cursor to "adopt" their virtual 3D animated Dogz and Catz as puppies and kittens, and play with, raise, and nurture them in the same manner that one would with real pets, with petting, toys, food, going places, behavior training, and so on. Babyz later added more sophisticated facial expressions, baby-talk natural language, and the beginnings of voice recognition. Both kids and adults enjoyed the products: over two million units were sold worldwide, and hundreds of fan websites were created that remain active to this day.

Petz and Babyz raised the bar for what virtual characters could be and made it clear that users want to form emotional relationships with them. They were the first AI-based animated interactive characters with rich personality and emotion that could immediately respond to the user's direct moment-by-moment action and gesture in a expressive, performance-like way. The characters were designed to be familiar and recognizable (e.g. grumpy bulldogs, cute scaredy cats, snobby poodles, aggressive hunter cats, and so on), leveraging off of the user's own knowledge and expectations for dramatic effect. By creating a broad base of interactive behaviors and stocking the virtual environments with objects and props designed for playful mischief and humor, it laid fertile ground for interactive narrative to emerge through play. Petz and Babyz owners posted hundreds of messages on the PF.Magic website bulletin board and on their own websites describing their experiences and emotional relationships with their individual Petz and Babyz.

\section{Joseph Tabbi}

Thinking back on some of the conferences that took place during the recent Great Migration from print to screen, I recall the palpable excitement, the feeling that an entire discipline and its writing practices were being newly invented, and newly named even in the conference titles: "Spectatorship" (Maastricht, Holland, November 1999), "Topologies for the Millennium" (Hanover, Germany, January 2000), "The Future of the Page" (Saskatchewan, Canada, June 2000), "Book/Ends" (Albany, New York, October 2000), the First Electronic Literature Organization Awards Cer- 
emony (New York City, April 2001). The scholars and literary critics who attended these and similar events were quick to get with the discourse. It was as if cyberspace had given us a vast textual playground where we could finally enact the thought experiments of poststructuralist theory from the preceding decades or realize the potentials imagined in the fiction-William Gibson's Neuromancer of 1985-that gave us the word "cyberspace." Still, there was a feeling, occasionally voiced in public, that the radical changes we were talking about with such precision and passion had done little to alter our own institutional practice: there we were, for the most part following a panel or a lecture format, reading papers, fielding questions from the audience, devising arguments, giving demos. Illustrations were optional. Web shots and sound clips entirely at the presenter's risk.

Sometimes I wondered whether the academic conference itself, and its traditional justifications, didn't need repurposing now that travel was no longer necessary in order for distant scholars to exchange information. Were the conferences even about information at all? Or were they more an occasion for a certain kind of performance?

Trace Redell, Litmixer (2001)

$<$ http://www.altx.com/ebr/ebr12/litmix/index.htm>

This is what critical writing could look like once scholars and critics begin making use of the performative possibilities within networked environments. With his software groovebox, Reddell applies the tools and strategies of the DJ to the performance of literary interpretation and critical speculation. Jacques Derrida's essay, "Plato's Pharmakon," becomes in Reddell's hands not so much a master text as a set of recording masters, less a source of supporting citations than a sampling source to be played off against related discourses on music, drugs, technology. And it's all presented in the context of a "user's manual," a rhetorical framework that both participates in techno-culture and invites further activity on the part of the reader/ listener/user.

Joseph Tabbi (editor), The Cybertext Debate (2001-2002)

$<$ http://www.altx.com/ebr/ebr11>

Reddell's piece happened to be published in the Web journal I edit, the electronic book review, at the very moment when several contributors were debating the question of whether we should retire the word "hypertext" and speak instead of "cybertexts." The stimulus for the debate was a review by an American creative writing student of Espen Aarseth's Cybertext (Johns Hopkins, 1997), which stimulated responses from a narratologist in Norway, who in turn provoked responses from a UCLA professor, two authors from Eastgate (the only commercial publisher of hypertext fiction and poetry), the director of the burgeoning Electronic Literature Organization (who had co-authored an award-winning web-based hypertext fiction), a new media critic at the University of Maryland concerned with the technological obsolescence (already!) of much electronic writing, a beginning professor 
who'd just completed a NEH seminar on electronic textuality, and a grad student who was dismayed to discover that the field he'd chosen for his dissertation was already being declared defunct.

Ewan Branda, Anne Burdick, and Joseph Tabbi, ebr 3.0 (2002)

$<$ http://www.electronicbookreview.com>

Whatever we critics end up calling it-hypertext, cybertext, or simply text (my preference)-my guess is that the decisive contributions to the cyber-debates will be those Web installations, like Reddell's, that enact their premises by using Web resources to their fullest, so as to keep the language alive and the conversation going.

Along these lines, we've recently redesigned $e b r$ itself so as to be more cyberactive. The release in February 2002 of $e b r$ version 3.0, a fully interactive, databasedriven Web interface, marks an appropriate culmination to the cyber-debates. The release features an in-house discussion among the journal editors whose outcome is the journal itself, while the new interface delivers on ebr's promise-stated in its very first issue-to actively participate in the Web environment it critiques.

One major innovation, which we believe is specific and (dare we say) natural to Web environments, is the elimination of periodical "issues." The $e b r$ editors felt that periodical publication was an unexamined legacy from print culture and "issues" were hardly necessary now that contents could be keyed to a database, searched, and organized in various ways. So, instead of "issues," the journal now offers "threads," groupings of essays, reviews, and Web projects on a specific theme or topic. The journal can now be updated at any time (our audience is notified by e-mail when new material is posted). And all ebr content is current (another major difference from a printed archive).

Raymond Federman and Anne Burdick, Eating Books (1998) $<$ http://www.altx.com/ebr/ebr7/ebr7.htm>

If Moby has written the loudest song in the universe, Raymond Federman's Eating Books has to be the most linear hypertext in the universe: an essay-narrative that can only be read by horizontal scrolling through a single long line of text that, as it moves past, disappears from view. There is no going back, no re-reading, no second chance (short of reloading the whole thing). I recommend this Web project, a now classic image/narrative collaboration with text by Federman and design by Anne Burdick, because it demonstrates that the link is not, and never was, the defining feature of "electronic literature," as many commentators claimed in the early, heady days of hypertext. Neither was "non-linearity," and neither was a freeplay of competing voices and visions, none more distinct than any other (as many supposed who were hardly listening and only scanning, not watching). None of these features are peculiar to Web environments or the writing potentially produced there. Rather, what's definitive about Federman's and Burdick's collaboration is that the authors willingly accept the constraints of the medium; they work 
within these constraints, play off them, and in so doing make the medium their own. The text requires attention to the present; to what's passing before us now. It begins, it takes a certain amount of time, and it ends. It takes responsibility for what it consumes, and it doesn't pretend (like those readers who are eager for the next link, anxious to branch out, to consume more) that meaning exists anywhere but in the text you are reading, at the time you are reading it, through connections and verbal/visual patterns that the work, and nothing else, generates out of itself from within the constraints of the Web environment.

\title{
Rob Wittig
}

Rob Wittig, Blue Company $(2001,2002)$

$<$ http://www.tank20.com/bluecompany>

In May 2002, TANK20 presented the second performance of Blue Company, following the underground hit premiere performance of 2001 .

*Thundering Announcer Voice*

"In a world where corporations are falling, warlords rule, and time is out of kilter, one young employee must try to keep his soul alive using the only lifeline he has left-his e-mail!"

For a month, as a subscriber, you receive one illustrated e-mail a day from a shy, witty young white-collar workerbee who has suffered a really bad job transfer. He's been transferred to Italy (which is good). But he's been transferred to the Renaissance, the year 1368 (which, as subscribers discover, can be really bad).

His business unit, masquerading as a small, free-lance fighting force, has to make its way to Milan on a top-secret mission for the corporation. To add a twist of comic voyeurism to the story, the e-mails are, in part, designed to woo a young woman whom the correspondent began to court before his disastrous transfer.

Subscribers to the first performance said, "I found myself rushing to my e-mail to get the next installment," "I was surprised at how big a part of my life Blue Company became. When it ended I was pleading for more," and "It was a powerful experience to read a daily novel that included daily news."

Keith Gessen of The New Republic Online wrote:

\begin{abstract}
Wittig's experiment, though technically simple, is a perfect example of a distribution mechanism taking on the properties of literary innovation. A novel that reaches the reader via e-mail, on a daily basis, will be read differently, written differently, and evolve into a different animal. It could free the novel from its unhappy existence as the least performative (and therefore the most product-like) of art forms.
\end{abstract}

Shelley Jackson and Pamela Jackson, The Doll Games (2001) $<$ http://www.ineradicablestain.com/dollgames/>

What a fine writer Shelley Jackson is! In fact, she is held by many to be the most important author of literary hypertext in the ' 90 s, on the basis of her breathtakingly 
smart and well-crafted Patchwork Girl by Mary/Shelley \& Herself(Eastgate, 1995). Patchwork Girl is a resewing of narrative seeds planted in Mary Shelley's Frankenstein, and concerns a female monster linking her various body parts back to their original owners and offering remixes/retellings of Mary's story. Patchwork Girl uses hyperlinks as both navigation and metaphor, drawing parallels between sewing, writing, women's lives, historiography, and Web work that are truly profound and not just easy puns. A must read.

The Doll Games, a collaboration between Shelley Jackson and her sister Pamela, takes an attitude of dignified (though tongue-in-cheek) scholarship and applies it to the study of the obsessive and elaborate games the two played with a box full of battered dolls as children. Shelley and Pamela's rediscovery of that box, as adults, inspired the project.

In The Doll Games, the calm force of observation applied to the wildly emotional acting out that the "doll games" embodied produces a result that is intelligent, often hysterically funny, and intensely creepy. The subtle cross-commentary and tussles of historical revisionism between the two sisters add an interesting tension to the work. Shelley's magnificent command of vocabulary allows her to drop just the right/wrong word at the right/wrong time-a hallmark of her style. The design of the site-its darkness and the wonderful photography that offers us glimpses of the maimed, worshipped, and often ill-used dolls themselves-makes good use of the graphic design possibilities of the new medium.

Mez, -][selec][text: co][deP][1][oetry]_(2001)

$<$ http://www.netwurkerz.de/mez/selectext/index.htm>

The mysterious Mez is a netizen who, rumor has it, lives in Wollongong, Australia, but whose presence is felt world wide via her e-mails to various Web art and culture lists and her remixes of these e-mails (along with additional text) into literary works in Web form.

Mez's style, which makes liberal use of square brackets and other punctuation to divide words at their linguistic joints and offer multiple possible recombinations, is more than just superficial strangeness. Her years of practice at the keyboard (I have read her chat that she averages something like six hours a day in e-mail and other networked writing) have developed her into a deeply skilled stylist with a unique and intelligent relationship to written language.

Explosive, rational, coy, and angry at the same time, Mez's writing rips out of the screen from the first instant and never looks back. It is a refreshing reminder that we are free to forego the tired preambles and summaries and careful tropes and conventional scaffolding of writing and plunge right into the beautiful, awful heart of language - the way we do in our most intimate e-mails and most secret journals.

Mez's writing earns the highest accolade from other writers-imitation. Mez's style (she calls it Mezangelle) is infectious, and it would be no surprise to see it attract other practitioners in the same way that music styles (Reggae, Techno) gather adherents and become movements. 
Barry Smylie, assorted web projects (mid 1990s-present)

<http:// barrysmylie.com> and <http://barrysmylie.com/iliad/iliad000.htm>

Barry Smylie is one of the best of the handful of electronic literature practitioners who is equally comfortable in words, images, and design. His site is an anthology of work that is both pleasurable on its own account and forms a rich collection of examples, clues, and techniques that all budding Web workers should study.

While so many Web artists invest countless hours in elaborate programming that yields garbled and frustrating (and often simply boring) results, Barry Smylie and his collaborators use simple techniques with an exquisite sensitivity to the user's experience. Nothing is allowed to mystify gratuitously. The rich mysteries in Smylie's work are purposeful, and one feels the basic companionship of the creator that is present in many mature art forms and inadvertently absent from much new and experimental work.

Smylie has the knack of matching his artistic goals to both his artistic means and the limits of the medium. The pieces (look especially at "Town and Country" in the "stories" section and "Toon" in the "multimedia" section) are small in scope, and they work completely. This is high praise in a Web world where so many projects are too ambitious in scope and hardly work at all.

One of Smylie's most impressive recent projects is a retelling of Homer's Iliad, using contemporary imagery, flash animations, and multimedia to make a classic tale accessible to a new audience. Smylie is collaborating on the Iliad project with Ryan Douglas, Susan Katz, and Jeff Wietor. The project is a serial work in progress. Smylie writes,

In the beginning I wanted the Iliad to reflect the process of the media transformation and convinced Jeff to let me do it. Homer couldn't show us his writing of it as a part of the show and the printmakers and their translators couldn't show us their work (its techniques and development as performance) either. We can, we are, and we do expose the process and the new technologies as they come on-line and as we become familiar with the new techniques they present to us. 